\title{
Diffuse bronchoalveolar carcinoma
}

\section{Xiang-Dong MU*}

Department of Respiratory and Critical Care Medicine, Peking University First Hospital, No.8 Xishiku Street, Xicheng District, Beijing, PR China

A 36-year-old female farmer presented with dry cough for 3 months and dyspnea for 20 days. On admission to our hospital, physical examination showed bilateral pulmonary crepitus. Analysis of arterial gas on room air revealed hypoxemia. Pulmonary function testing showed a forced vital capacity of $39 \%$ and a diffusion capacity of $54 \%$ of the predicted values. Chest radiography (Figure 1) showed bilateral diffuse miliary nodules; chest computed tomography (Figure 2) showed diffuse disseminated small nodules and partially confluent to form larger nodules or consolidations. Pathological examination of transbronchial biopsy (Figure 3) showed lepidic growth of nonmucinous cuboidal cells along intact and mildly thickened alveolar septa, which was diagnosed as nonmucinous bronchoalveolar carcinoma. The mutation of EGFR gene was negative. Unfortunately, the patient died from respiratory failure 2 months later.

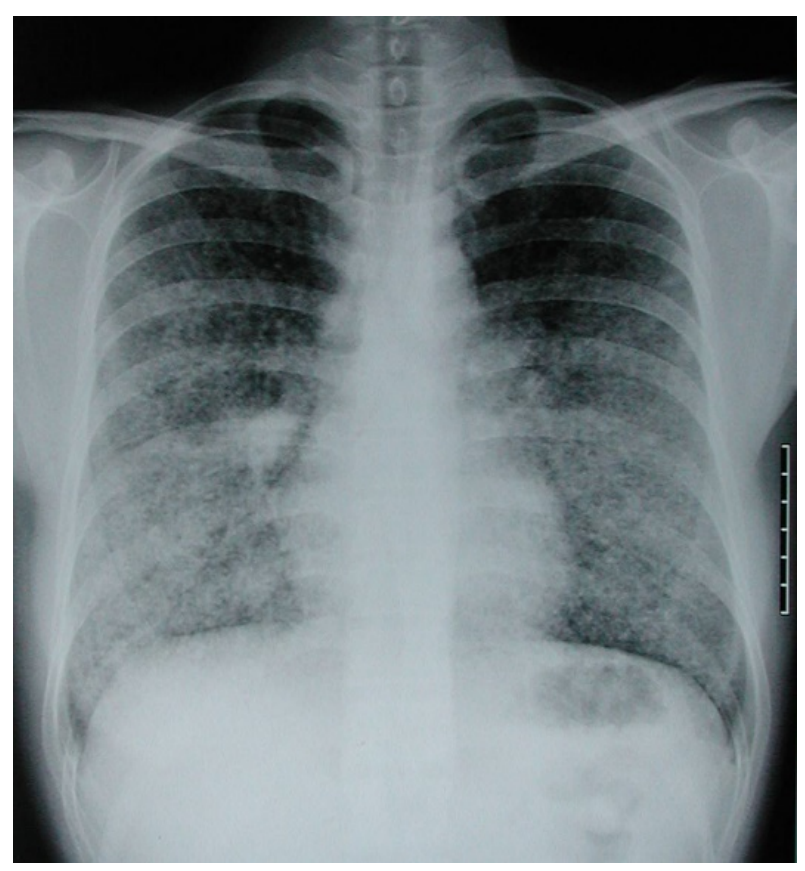

Figure 1. Chest radiography

Copyright: (C2017 Xiang-Dong MU. This is an open-access article distributed under the terms of the Creative Commons Attribution License, which permits unrestricted use, distribution, and reproduction in any medium, provided the original author and source are credited.

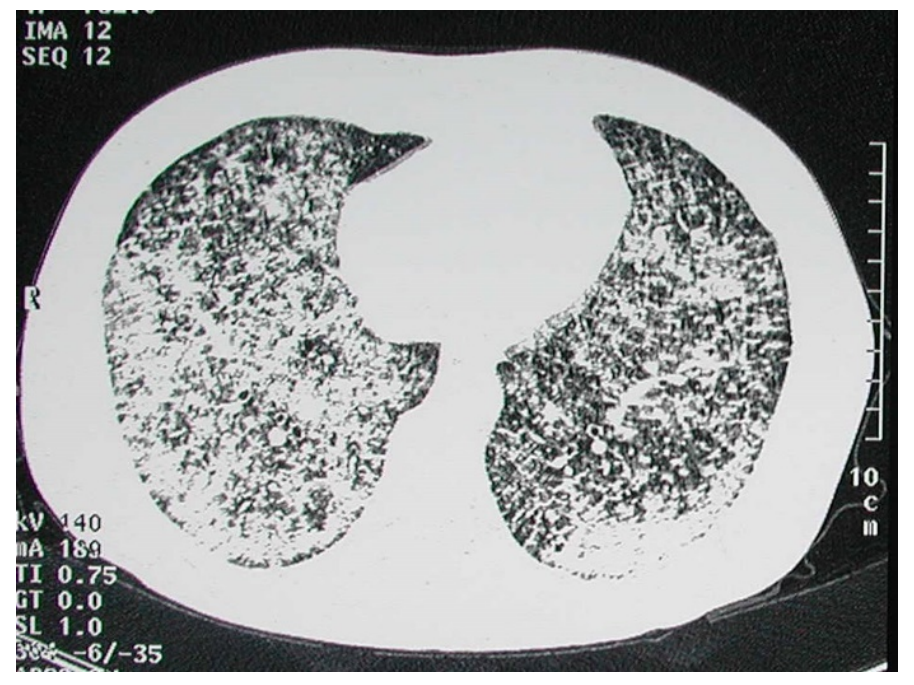

Figure 2. Chest computed tomography

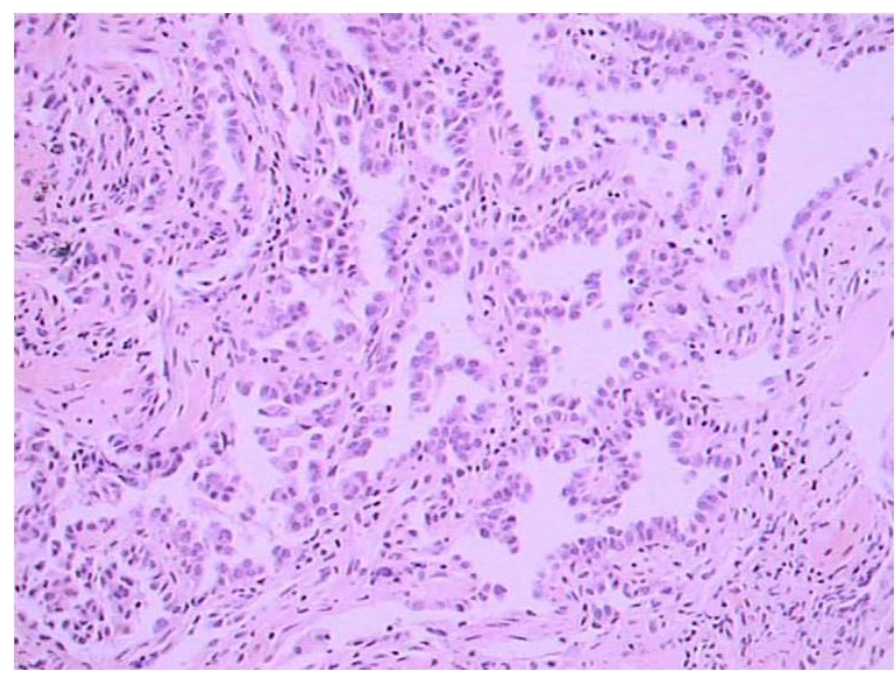

Figure 3. Pathological examination of transbronchial biopsy

Correspondence to: Xiang-dong MU, Department of Respiratory and Critical Care Medicine, Peking University First Hospital, Beijing 100034, China, Tel: 861083575753; E-mail: muxiangdong@medmail.com.cn

Received: June 28, 2017; Accepted: July 18, 2017; Published: July 20, 2017 